\title{
Dyslipidaemia and rheumatoid arthritis
}

In this issue of the Annals of the Rheumatic Diseases, Munro and colleagues ${ }^{1}$ report a comparative study of intramuscular gold and hydroxychloroquine in rheumatoid arthritis (RA). They demonstrate a beneficial effect of hydroxychloroquine on lipid profiles compared with gold and suggest that hydroxychloroquine might be considered for RA patients at adverse cardiovascular risk.

Should rheumatologists be interested in their patients' cardiovascular and lipid status? The answer to this question is an unqualified 'yes'. Several studies suggest that cardiovascular diseases account for about half of all deaths in RA. ${ }^{2}$ Cardiovascular deaths are more pronounced in the younger age group ( $<55$ years), and may contribute to the substantial reduction in life expectancy, with estimates of standardised mortality ratios ranging from 1.1 to $3 .^{3}$

We previously suggested that cardiovascular disease in RA may result from accelerated atherosclerosis caused by clinical or subclinical vasculitis. ${ }^{4}$ The main determinants of cardiovascular risk in the general population, however, are the concentrations of serum low density lipoprotein (LDL) and high density lipoprotein (HDL) cholesterol. In men who are middle aged or over, a ratio of total to HDL cholesterol over 5 associates with increased risk of a first myocardial infarction. ${ }^{5}$ Oxidative modification of LDL may also be important and it is of interest that oxidised LDL has been noted in RA synovial biopsy specimens. ${ }^{6}$ Products of LDL oxidation may be recognised by the scavenger receptor leading to increased uptake of the modified lipoprotein particle by macrophages; they may be directly cytotoxic to endothelial cells, chemotactic for inflammatory cells, and cause functional changes in smooth muscle. ${ }^{7}$ The inflammatory environment and disturbed antioxidant mechanisms in $\mathrm{RA}^{8}$ may promote LDL oxidation, thereby facilitating atherogenesis at lower ambient lipid concentrations and placing RA patients at higher cardiovascular risk. Though attractive, this hypothesis remains to be tested.

Lipid metabolism in RA has received only modest attention. With the exception of a single study, ${ }^{9}$ most investigators agree that total, LDL and HDL cholesterol and triglycerides are reduced in active RA compared with inactive disease, non-inflammatory arthritis or normal controls $^{10-13}$ (table 1), with inverse correlation between lipid values and the acute phase response.

With the exception of low HDL, which is an adverse prognostic factor, the remaining lipid profile in active RA may appear advantageous. It is however difficult to predict the overall impact of individual lipid changes on RA patients, during the course of the disease though for the general population the risk for a first myocardial infarction depends on the total to HDL cholesterol ratio rather than their absolute values. ${ }^{5}$ This has not been resolved in previous studies of RA, but Munro found that the median values were promisingly under 5 for both treatment groups. Lipoprotein (a), an important independent factor in atherogenesis and thrombogenesis ${ }^{14}$ is increased in RA, correlating positively with the acute phase response. ${ }^{12} 15$
The apparent reduction of total cholesterol may result from reduced synthesis, increased clearance via the scavenger receptor pathway or increased oxidation ${ }^{10}$ triggered by the inflammatory process. Alternatively the presence of circulating autoantibodies to VLDL and LDL in active $\mathrm{RA}^{16}$ may be responsible. These may also have pre-atherogenic effects on the vascular wall by forming immune complexes.

Effects of anti-rheumatic treatment should also be taken into account. Non-steroidal anti-inflammatory drugs do not seem to have any effect on lipids in $\mathrm{RA}^{11}$ and a study from 1976 suggested that long term anti-inflammatory aspirin use did not convey cardiovascular protection. ${ }^{17}$ The lipid raising effects of corticosteroids are well reported ${ }^{18}$ though their use in RA may not be associated with an increased risk for a cardiovascular event. ${ }^{19}{ }^{20}$ No large prospective studies have assessed the effect of slow acting antirheumatic drugs (SAARDs) on lipids. Control of disease activity by certain SAARDs may lead to 'normalisation' of the lipid profile (increase of total, LDL and HDL cholesterol) ${ }^{11}$ - this is supported by Munro's data ${ }^{1}$ for intramuscular gold, which is not thought to have a direct effect on lipid metabolism. Cyclosporin may have an enhanced effect as some reports suggest that it contributes to accelerated atherosclerosis in subjects who have undergone renal transplantation. ${ }^{21}$

In contrast, the antimalarial agents seem to hold an exceptional position with regard to their effects on lipids. Wallace et al have previously reported a $15-20 \%$ decrease in serum triglyceride, cholesterol, and LDL concentrations and a reversal of the lipid raising effects of corticosteroids in 150 patients with lupus and $\mathrm{RA},{ }^{22}$ while in Svenson's study ${ }^{11}$ in RA chloroquine was found to differ from other agents by reducing the values of cholesterol and triglycerides. It has been suggested that chloroquine may lower cholesterol by inhibiting the proteolysis of internalised cholesterol esters leading to increased LDL receptor values. ${ }^{23}$ Munro ${ }^{1}$ now reports substantial changes in HDL cholesterol and \% HDL cholesterol (HDL cholesterol expressed as a percentage of total cholesterol), reaching significance between groups at six months (median HDL: $+15 \%$ for hydroxychloroquine, $-12 \%$ for gold; median $\%$ HDL: $+9 \%$ for hydroxychloroquine, $-15 \%$ for gold). Triglycerides rose by $0.5 \mathrm{mmol} / 1$ in the gold group (31\%), a finding that may also have adverse cardiovascular impact. ${ }^{24}$

To place such results in context, lipid lowering diets reduce serum total cholesterol concentrations by $2 \%$ to $13 \%,{ }^{25}$ while statins generally cause a 20 to $30 \%$ fall of cholesterol and 15\% rise of HDL. A $10 \%$ fall in serum total cholesterol concentration reduces the risk of death from coronary heart disease by $10 \%$ (95\% confidence intervals (CI) $3 \%, 16 \%$ ) and of non-fatal myocardial infarction by $21 \%(95 \%$ CI $15 \%, 27 \%) .{ }^{26} 27$ Pravastatin reduced total cholesterol by $20 \%$ and LDL cholesterol by $26 \%$ in the WOSCOPS study of hypercholesterolaemic

Table 1 Fasting serum cholesterol and triglycerides in active and inactive $R A$

\begin{tabular}{|c|c|c|c|c|c|c|}
\hline \multirow[b]{2}{*}{ Lipid } & \multicolumn{2}{|c|}{ Active $R A^{*}$} & \multicolumn{2}{|c|}{ Inactive $R A^{\star}$} & \multicolumn{2}{|c|}{ ranked ANOVA } \\
\hline & $n$ & median $(I Q R)$ & $n$ & median $(I Q R)$ & $z$ & $p$ Value \\
\hline $\begin{array}{l}\text { Cholesterol } \\
\text { Triglyceride }\end{array}$ & $\begin{array}{l}57 \\
51\end{array}$ & $\begin{array}{l}4.83(4-5.75) \\
1.47(1.19-1.65)\end{array}$ & $\begin{array}{l}35 \\
30\end{array}$ & $\begin{array}{l}5.47(5.08-6.57) \\
1.5(1.02-1.87)\end{array}$ & $\begin{array}{l}3.6 \\
0.6\end{array}$ & $\begin{array}{l}0.0004 \\
0.54\end{array}$ \\
\hline
\end{tabular}

ॠActive RA defined as those requiring initiation or change in SAARD, inactive RA as those with minimal joint inflammation and low ESR and CRP. Unpublished data from Mulherin et al. ${ }^{31}$ 
subjects, equating to a $31 \%$ reduction in risk of non-fatal myocardial infarction or death by five years. ${ }^{28}$

It seems therefore that the advantageous effects of antimalarial drugs on lipid profile compare well with those achieved by using specific lipid lowering treatment. In this respect, hydroxychloroquine may offer advantages over other SAARDs in the treatment of RA patients at increased cardiovascular risk. With the shift to aggressive early treatment of RA, however, it is more likely to be used in combination therapy rather than alone. ${ }^{29}$

What are the implications for clinical practice? Modifiable cardiovascular risk factors should be considered including smoking, diabetes, hypertension, and hormone replacement therapy in post-menopausal women (oestrogen and progesterone can reduce the risk of a first myocardial infarction by $50 \%) \cdot{ }^{30}$ Attention must be paid to lipids for those with a previous history of a cardiovascular event. Hydroxychloroquine should be considered in combination therapy regimens for patients with severe RA and adverse cardiovascular risk. Further research examining the relation between cardiovascular mortality in RA, dyslipidaemia, and the effects of chronic inflammation on vascular biology, lipids, and atherosclerosis might prove fruitful both to rheumatologists and cardiologists.

R D SITUNAYAKE Department of Rheumatology, City Hospital NHS Trust, Winson Green, Dudley Road, Birmingham B18 7QH

Department of Rheumatology, Dudley Group of Hospitals NHS Trust, Guest Hospital, Tipton Road, Dudley, West Midlands

Correspondence to: Dr R D Situnayake.

1 Munro R, Morrison E, McDonald AG, Hunter JA, Madhok R, Capell HA Effect of disease modifying agents on the lipid profiles of patients with rheumatoid arthritis. Ann Rheum Dis 1997;56:374-7.

2 Reilly PA, Cosh JA, Maddison PJ, Rasker JJ, Silman AJ. Mortality and survival in rheumatoid arthritis: a 25 year prospective study of 100 patients. Ann Rheum Dis 1990;49:363-9.

3 Myllykangas-Luosojarvi RA, Aho K, Isomaki HA. Mortality in rheumatoid arthritis. Seminars in Arthritis and Rheumatism 1995;25:193-202.

4 Bacon PA, Kitas GD. The significance of vascular inflammation in rheumatoid arthritis. Ann Rheum Dis 1994;53:621-2.

5 Stampfer MJ, Sacks FM, Savini S, Willett WC, Henneckens CH. A prospective study of cholesterol, apolipoproteins, and the risk of prospective study of cholesterol, apolipoproteins,

6 Winyard PG, Tatzber F, Esterbauer H, Kus ML, Blake DR, Morris CJ. Presence of foam cells containing oxidised low density lipoprotein in the synovial membrane from patients with rheumatoid arthritis. Ann Rheum Dis 1993;52:677-80.

7 Offermann MK, Medford RM. Antioxidants and atherosclerosis: a molecular perspective. Heart Disease and Stroke 1994;3:52-7.
8 Situnayake RD, Thurnham DI, Kootathep S, Chirico S, Lunec J, Davis M, et al. Chain breaking antioxidant status in rheumatoid arthritis: clinical and et al. Chain breaking antioxidant status in rheumatoid

9 Lakatos J, Harsagyi A. Serum total, HDL, LDL cholesterol and triglyceride levels in patients with rheumatoid arthritis. Clin Biochem 1988;21:93-6.

10 Svenson KL, Lithell H, Hallgren R, Selinus I, Vessby B. Serum lipoprotein in active rheumatoid arthritis and other chronic inflammatory arthritides. I. Relativity to inflammatory activity. Arch Intern Med 1987;147:1912-6.

11 Svenson KL, Lithell H, Hallgren R, Vessby B. Serum lipoprotein in active rheumatoid arthritis and other chronic inflammatory arthritides. II. Effects of antiinflammatory and disease-modifying drug treatment. Arch Intern Med 1987;147:1917-20

12 Rantapaa-Dahlqvist S, Wallberg-Jonsson S, Dahlen G. Lipoprotein (a), lipids and lipoproteins in patients with rheumatoid arthritis. Ann Rheum Dis 1991;50:366-8

13 Lazarevic MB, Vitic J, Mladenovic V, Myones BL, Skosey JL, Swedler WI. Dyslipoproteinemia in the course of active rheumatoid arthritis. Seminars in Arthritis and Rheumatism 1992;22:172-8.

14 Lip GYH, Jones AF. Lipoprotein (a) and vascular disease: thrombogenesis and atherogenesis. Q J Med 1995;88:529-39.

15 Wallberg-Jonsson S, Uddhammar A, Dahlen G, Rantapaa-Dahlqvist S. Lipoprotein (a) in relation to the acute phase reaction in patients with rheumatoid arthritis and polymyalgia rheumatica. Scand J Clin Lab Invest 1995;55:309-15.

16 Lazarevic MB, Vitic J, Myones BL, Mladenovic V, Nanusevic N, Skosey JL, et al. Antilipoprotein antibodies in rheumatoid arthritis. Seminars in Arthritis and Rheumatism 1993;22:385-91.

17 Monson RR, Hall AP. Mortality among arthritics. J Chron Dis 1976;29:459-67.

18 Ettinger WH, Klinefelter HF, Kwiterowich PO. The effects of short term low dose corticosteroids on plasma lipoprotein lipids. Atherosclerosis low dose cortic

19 Wallberg-Jonsson S, Ohman M, Rantapaa Dahlqvist S. Cardiovascular morbidity and mortality in patients with seropositive rheumatoid arthritis in Northern Sweden. J Rheumatol 1997;24:445-51.

20 Raynauld J-P. Cardiovascular mortality in rheumatoid arthritis: how harmful are corticosteroids? J Rheumatol 1997;24:415-6.

21 Vathsala A, Weinberg RB, Schoenberg L, Grevel J, Dunn J, Goldstein RA, et al. Lipid abnormalities in renal transplant recipients treated with cyclosporine. Transplant Proc 1989;21:3670-2.

22 Wallace DJ, Metzger AL, Stecher VJ, Turnbull BA, Kern PA. Cholesterol lowering effect of hydroxychloroquine in patients with rheumatic disease: reversal of deleterious effects of steroids. Am J Med 1990;89:322-6.

23 Benyen AC. Can chloroquine be of value in the treatment of hypercholesterolaemia? Artery 1986;13:340-51.

24 Hokanson JE, Austin MA. Plasma triglyceride level is a risk factor for cardiovascular disease independent of high-density lipoprotein cholesterol level: a meta-analysis of population based prospective studies. J Cardiovasc level: a meta-analysis 0

25 Ramsay LE, Yeo WW, Jackson PR. Dietary reduction of serum cholesterol: time to think again. BMJ 1991;303:953-7.

26 Law MR, Wald NJ,NJ Thompson NJ . By how much and how quickly does reduction in serum cholesterol concentration lower risk of IHD? BMJ 1994;308:367-73.

27 Anonymous. Management of hyperlipidaemia. Drug Ther Bull 1996;34:8993

28 Shepherd J, Cobbe SM, Ford I, Isles CG, Lorimer AR, MacFarlane PW, et $a l$. The West of Scotland Coronary Prevention Study Group. Prevention of coronary heart disease with pravastatin in men with hypercholesterolaemia. N Engl J Med 1995;333:1301-7.

29 Duncan MR, Capell HA. The use of antimalarials in combination with other disease modifying agents in RA - the British experience. Lupus 1996;5 (suppl 1):s50-8.

30 Falkeborn M, Persson I, Adami HO, Bergstrom R, Eaker E, Lithell H, et al. The risk of acute myocardial infarction after oestrogen and oestrogen progesterone replacement. Br J Obstet Gynaecol 1992;99:821-8.

31 Mulherin DM, Thurnham DI, Situnayake RD. Glutathione reductase activity, riboflavin status and disease activity in rheumatoid arthritis. Ann Rheum Dis 1996;55:837-40. 